\title{
(2) OPEN ACCESS \\ Hospice care access inequalities: a systematic review and narrative synthesis
}

\author{
Jake Tobin, ${ }^{1}$ Alice Rogers, ${ }^{1}$ Isaac Winterburn, ${ }^{2}$ Sebastian Tullie, ${ }^{1}$ \\ Asanish Kalyanasundaram, ${ }^{1}$ Isla Kuhn, ${ }^{3}$ Stephen Barclay (i) ${ }^{2}$
}

- Prepublication history and additional material is published online only. To view please visit the journal online (http://dx.doi.org/10.1136/ bmjspcare-2020-002719).

${ }^{1}$ School of Clinical Medicine, University of Cambridge, Cambridge, UK

${ }^{2}$ Primary Care Unit, Department of Public Health and Primary Care, University of Cambridge, Cambridge, UK

${ }^{3}$ Medical Library, School of Clinical Medicine, University of Cambridge, Cambridge, UK

\section{Correspondence to}

Dr Stephen Barclay, Primary

Care Unit, Department of Public Health and Primary Care, University of Cambridge Cambridge CB2 1TN, UK sigb2@medschl.cam.ac.uk

Received 26 September 2020 Revised 9 January 2021 Accepted 17 January 2021

\section{Check for updates}

(C) Author(s) (or their employer(s)) 2021. Re-use permitted under CC BY-NC. No commercial re-use. See rights and permissions. Published by BMJ

To cite: Tobin J, Rogers A, Winterburn I, et al. BMJ Supportive \& Palliative

Care Epub ahead of

print: [please include Day

Month Year]. doi:10.1136/

bmjspcare-2020-002719

\section{ABSTRACT}

Background Inequalities in access to hospice care is a source of considerable concern; white, middle-class, middle-aged patients with cancer have traditionally been over-represented in hospice populations.

Objective To identify from the literature the demographic characteristics of those who access hospice care more often, focusing on: diagnosis, age, gender, marital status, ethnicity, geography and socioeconomic status.

Design Systematic literature review and narrative synthesis.

Method Searches of Medline, PsycINFO, CINAHL, Web of Science, Assia and Embase databases from January 1987 to end September 2019 were conducted. Inclusion criteria were peer-reviewed studies of adult patients in the UK, Australia, New Zealand and Canada, receiving inpatient, day, outpatient and community hospice care. Of the 45937 titles retrieved, 130 met the inclusion criteria. Narrative synthesis of extracted data was conducted.

Results An extensive literature search demonstrates persistent inequalities in hospice care provision: patients without cancer, the oldest old, ethnic minorities and those living in rural or deprived areas are under-represented in hospice populations. The effect of gender and marital status is inconsistent. There is a limited literature concerning hospice service access for the LGBTQ+ community, homeless people and those living with HIV/AIDS, diabetes and cystic fibrosis.

Conclusion Barriers of prognostic uncertainty, institutional cultures, particular needs of certain groups and lack of public awareness of hospice services remain substantial challenges to the hospice movement in ensuring equitable access for all.

\section{INTRODUCTION}

When the modern hospice movement started in 1967 with Dame Cicely

\section{Key messages}

What was already known?

- Hospice services traditionally mainly care for people with cancer.

- National policies have repeatedly called for greater equality of access to hospice care provision

What are the new findings?

- Certain groups continue to have unequal access to hospice care; the oldest old, ethnic minorities, people with non-cancer illness, those living in rural areas and areas of social deprivation.

- A combination of prognostic uncertainty, institutional cultures, unique needs of particular groups and a lack of public awareness of services exacerbate these problems.

What is their significance?

- Equity of access to hospice care for all is urgently needed and remains a major challenge for the hospice movement.

- Innovative and collaborative services need to be developed to meet the diverse needs of the whole community.

Saunders opening St. Christopher's Hospice in South London, the main focus of the early hospices was on excellence in the holistic palliative and end-of-life care of patients with cancer. Since those early days, hospices have sought to broaden their reach to include those with noncancer diagnoses and other underserved groups.

In addition to inpatient beds, hospice care commonly includes specialist home care and community teams, Macmillan and Marie Curie nursing services, hospice at home services, day therapy and outpatient consultations. Working alongside colleagues in General Practice and District Nursing and hospital Palliative Care 
teams, hospices are often leaders in education and local service developments.

However, inequalities of hospice provision persist. Of the 528973 deaths in England and Wales in 2019, $71.5 \%(378,108)$ were from non-cancer conditions and $28.5 \%(150,865)$ from cancer. ${ }^{1}$ Hospices were the place of death for $1.2 \%(4,503)$ of non-cancer deaths and $16.5 \%(24,925)$ of cancer deaths. Of the 29428 deaths in hospices in 2019, $24925(84.7 \%)$ were from cancer and 4503 (15.3\%) from non-cancer. While many more people receive hospice care than die there, these figures suggest that patients with cancer remain disproportionately served by hospice care. National mortality statistics from Scotland and Northern Ireland are very similar.

Over recent years there has been growing recognition of the palliative care needs of people dying from non-cancer conditions, alongside the development of palliative care teams in hospitals and the community. While the proportion of non-cancer deaths occurring in hospice in England and Wales has increased over the past decade, from $7.8 \%$ in 2010 to $12.4 \%$ in 2015 and $15.3 \%$ in $2019,{ }^{2}$ patients without cancer remain under-represented in these data.

Diagnosis is not the only inequality that persists in hospice care provision; evidence suggesting that the oldest old (aged 85+) are also under-represented, alongside considerable disparities across geographical regions of the UK. ${ }^{1}$ To address these issues, there has been an impetus in many countries to improve the equity of palliative and end of life care provision. The 2008 UK Department of Health 'End of Life Care Strategy' promoted a 'vision for a good death' that is 'irrespective of age, gender, ethnicity, religious belief, disability, sexual orientation, diagnosis or socioeconomic status'. ${ }^{3}$ This was echoed in the 2015 'Ambitions for Palliative and End of Life Care', which emphasised that each person should have 'fair access to care'. ${ }^{4}$

We therefore undertook a systematic review of the literature to investigate the characteristics of those who access hospice services, focusing on the evidence concerning the presence and nature of any inequalities. In contrast to a 2015 rapid review focused on the UK literature between 2010 and $2015,{ }^{5}$ we undertook a systematic review of the literature from 1987 to 2019 and included studies from the UK, Canada, Australia and New Zealand.

\footnotetext{
Aims

To systematically review and synthesise the peerreviewed literature concerning referral to or receipt of hospice care with regards to eight characteristics: diagnosis and comorbid conditions; age; gender and sexuality; marital status; ethnicity and religion; geographical factors including rurality and distance to hospice; socioeconomic factors; other characteristics.
}

\section{Box 1 PubMed search strategy}

- ("Ethnicethnic Groupsgroups"[(Mesh]) OR ethnic differences $O R$ racial differences $O R$ poverty $O R$ deprivation $O R$ ethnicity $O R$ culture $O R$ minority $O R$ marital status $O R$ socioeconomic $O R$ age factors OR intellectual disabilities $O R$ rural $O R$ urban $O R$ demographic variation $O R$ location $O R$ sexuality $O R$ nationality $O R$ wealth $O R$ gender $O R$ cancer OR heart failure OR COPD OR Chronicchronic Obstructiveobstructive Pulmonarypulmonary Diseasedisease OR emphysema OR dementia OR Alzheimer's OR neurological OR multiple sclerosis OR motor neuroneneuron disease $\mathrm{OR}$ motor neuron disease $\mathrm{OR}$ cystic fibrosis $\mathrm{OR}$ haematological) AND

- (specialist palliative care OR hospice OR "Hospice Ca re" [(Mesh]) OR "Hospices" [(Mesh]) OR "Hospice and Palliative Care Nursing" [(Mesh]))

\section{METHODS}

Following an initial scoping search, inclusion and exclusion criteria were clarified and search strategies developed in discussion with the review team's Information Scientist (IK). Searches were undertaken for papers published between January 1987 (when Palliative Medicine became a recognised medical specialty in the UK) and the end of September 2019 in six databases: Medline, Embase and PsycINFO via OVID; CINAHL via EbscoHOST; ASSIA via Proquest; Web of Science. Additional searches included hand searches of Palliative Medicine and Journal of Palliative Care and reference and citation searches of included papers. Box 1 shows the PubMed search strategy.

\section{Inclusion and exclusion criteria}

Hospice care was broadly defined to include inpatient units and beds, day therapy, outpatients, hospice at home, community hospice teams, Macmillan and Marie Curie nurses, hospice chaplains and hospice social workers. Studies on deaths in hospice and referral to hospice services were included. Where studies included 'hospice' under a broader heading of 'specialist palliative care', they were included to ensure comprehensiveness. We restricted studies to those from countries with similar models of hospice care and health service provision: UK, Canada, Australia and New Zealand.

Publications were restricted to peer-reviewed journal papers, published in English and presenting new empirical data. Opinion pieces and editorials were excluded unless they contained original empirical data. Conference abstracts were included unless their data were subsequently published in full. The grey literature was not included. Publications on hospice care for people under 18 years of age were excluded, acknowledging the particular needs of children and young people. 


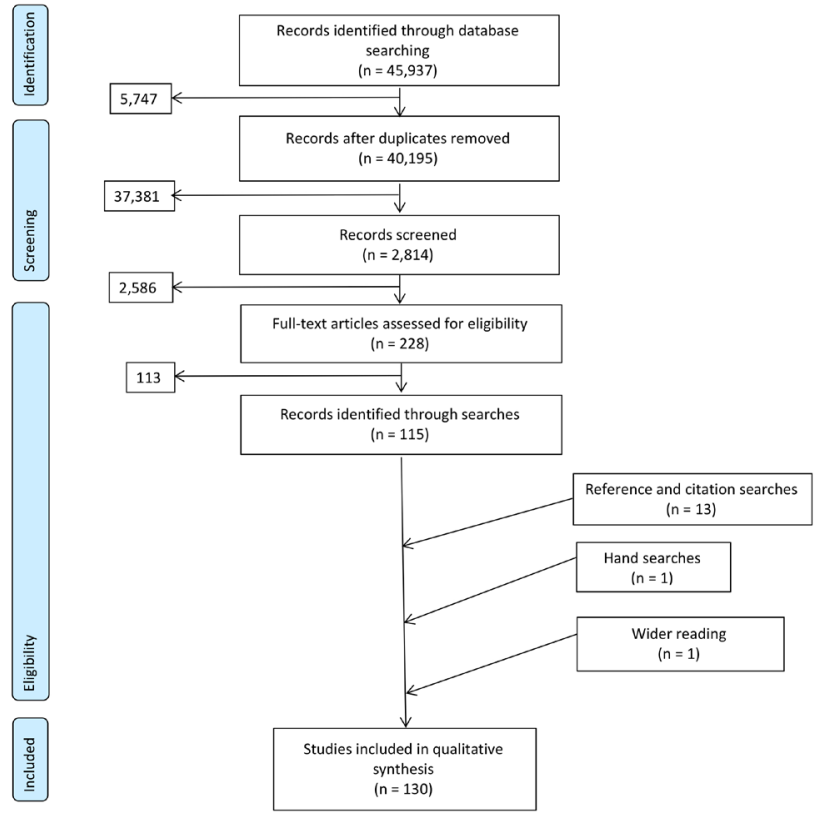

Figure 1 Preferred reporting items for systematic reviews and meta-analyses PRISMA diagram.

Search results were downloaded into EndNote X9 and duplicates removed. Titles, shortlisted abstracts and full-text articles were independently screened by AR, JT, ST and IW with uncertainty or disagreements resolved by discussion. From the 45937 records identified, 115 papers met the inclusion criteria. Reference and citation searches of included papers identified a further 13 papers, hand searches yielded a further paper and 1 additional paper was identified from our wider reading. A total of 130 papers were included in the narrative synthesis. Figure 1 presents the PRISMA diagram.

Authors (AR, JT, ST and IW) extracted data independently into a review-specific data extraction form which recorded characteristics of included studies and key findings relevant to the review questions (see online supplemental file 1).

Extracted data were entered into NVivo V.11 for qualitative analysis, with data synthesis using a narrative approach. ${ }^{67}$ This was chosen for its applicability to the synthesis of a range of qualitative and quantitative evidence. Three iterative stages were involved: (a) preliminary synthesis of each study from the data extraction forms; (b) study descriptions were grouped together and tabulated based on the review questions addressed and (c) an inductive thematic analysis to identify the main, recurrent and important evidence across the studies in answering the review questions.

Two researchers independently weighted each paper in terms of its strength, quality and contribution towards answering the review questions, using Gough's 'Weight of Evidence' (WoE) criteria with disagreements resolved by discussion (box 2). ${ }^{8}$

\section{Box 2 Gough's 'Weight of Evidence'}

- Gough D. Weight of evidence: a framework for the appraisal of the quality and relevance of evidence. Res Pap Educ 2007;22(2):213-28.

- Weight of Evidence A (WoE A). This is a generic and thus non-review-specific judgement about the coherence and integrity of the evidence in its own terms. The generally accepted criteria for evaluating the quality of this type of evidence by those who generally use and produce it.

- Weight of Evidence B (WoE B). This is a review-specific judgement about the appropriateness of that form of evidence for answering the review question, which is the fitness for purpose of that form of evidence.

- Weight of Evidence C (WoE C). This is a review-specific judgement about the relevance of the focus of the evidence for the review question. For example, a research study may not have the type of sample, the type of evidence gathering or analysis that is central to the review question or it may not have been undertaken in an appropriate context from which results can be generalised to the answer the review question.

- These three sets of judgements are then combined to form an overall assessment Weight of Evidence D (WoE D) of the extent that a study contributes evidence to answering a review question.

\section{RESULTS}

A summary of the included studies is presented in online supplemental file 2. Gough's 'Weight of Evidence ${ }^{8}$ for the 130 included papers assessed 49 as high, 54 medium and 27 low WoE.

Inequalities in access have been found in relation to diagnosis (reduced for non-malignant disease including heart failure, respiratory disease, renal and liver failure, mental health, learning disability, dementia and neurodegenerative disease (with the exception of motor neuron disease). The oldest old, people from ethnic minority groups, rural and more socioeconomically deprived area are under-represented in hospice services.

\section{Diagnosis}

Cancer versus non-cancer

A large literature of 29 papers, mostly high/medium WoE, evidence greater hospice referrals and/or deaths for patients with cancer compared with patients without cancer. ${ }^{9-37}$ There is evidence of increasing hospice access for people with non-malignant illness in the UK, ${ }^{31}$ Canada $^{18}$ and Australia. ${ }^{28}$

\section{Haematological malignancy}

Fifteen largely high WoE papers report lower hospice provision for those with haematological malignancies $^{16233138-49}$ with ORs compared with patients with cancer of around 0.4. ${ }^{23} 3841$ Recent years have seen increased deaths in UK hospices among patients with haematological malignancies. ${ }^{1631}$ 


\section{Heart failure}

Twelve studies, generally medium/low WoE, evidenced that patients with heart failure are rarely referred to hospice services. ${ }^{50-61}$ Referral rates of patients with heart failure are commonly lower than 5\% $0^{50} 52545758$ and patients with heart failure comprise less than 5\% of palliative care clinicians' workload. ${ }^{51}$

\section{Non-cancer respiratory disease}

All 11 papers reported low rates of hospice referral, ${ }^{34}$ 62-71 markedly lower than lung cancer, with some indication of increased referrals between 2006 and 2008.$^{67}$ Cystic fibrosis patients are underrepresented in hospices despite having significant symptom burden. ${ }^{62}$

\section{Renal failure}

Access to hospice care for patients with end-stage renal failure (ESRF) has been studied in the $\mathrm{UK}^{3472-76}$ and Australia ${ }^{77}$ with evidence of increasing collaboration between renal units and hospice teams in recent years. ${ }^{72}$ Hospice referrals are largely for those receiving conservative management for ESRF rather than people receiving renal replacement therapy. ${ }^{74577}$

Liver failure

The five medium/low WoE papers concerning patients with liver failure ${ }^{34-81}$ report them to represent less than $1 \%$ of hospice patient caseload ${ }^{79}$ with referral often occurring late in the course of the illness. ${ }^{34779}$

\section{Neurodegenerative Ddisease}

Papers concerning hospice care for patients with dementia, mostly medium WoE, identify that they are rarely referred for hospice care. ${ }^{34}{ }^{36}{ }^{82-84}$ Referral is more frequent if there is also a cancer diagnosis; ${ }^{82}$ otherwise, it occurs very late in the illness ${ }^{83}$ or not at all.

In contrast, patients with motor neuron disease often receive hospice care, ${ }^{348586}$ with hospice death more common than those with multiple sclerosis or Parkinson's disease.$^{87}$ Patients with multiple sclerosis are more likely to die in hospice if they also have a cancer diagnosis. ${ }^{88}$

Mental health and learning disability

The limited literature of medium/high WoE papers reports patients with schizophrenia rarely access hospice care ${ }^{89} 90$ and people with learning disabilities to be less likely to receive hospice care than the general population. ${ }^{30} 90$

\section{Age}

The extensive and high WoE literature concerning the 'oldest-old', people aged 85 years and older, reveals them to be under-represented in hospices across the UK, Australia, New Zealand and Canada. ${ }^{1011} 15162325$ 27-3436-3845 47 48 91-106 Centenarians seldom die in UK hospices. ${ }^{97} 98$ However, recent evidence suggests that more over 85-year-olds are accessing hospice care in the UK. ${ }^{11}{ }^{1631}$ One low WoE study found age not to affect hospice referral. ${ }^{107}$ One study reported the majority of patients accessing a hospice at home service were 78 years of age or older. ${ }^{11}$

\section{Gender and sexuality}

The literature concerning gender is inconsistent. Fifteen largely high WoE studies reported that women were more likely to access hospice care than men. ${ }^{15} 1624$ 26-293234384692108 However, eight high WoE studies suggested the reverse, ${ }^{10} 112531102103109110$ and seven high/medium WoE studies reported no differences in access based on gender. ${ }^{45} 489199107111112$ No papers were identified concerning LGBTQ+ populations, transgender patients or sexuality of couples.

\section{Marital status}

The literature concerning marital status is also inconsistent. While many high and medium WoE studies found married individuals were more likely to access hospice services, ${ }^{16} 24 \quad 27-2931-33 \quad 38102$ other studies (mostly medium WoE) found marital status to be unrelated to hospice access. ${ }^{9197107108111}$

\section{Ethnicity and religion}

Of the large, mainly high WoE literature concerning ethnicity, the great majority of studies report certain ethnic minority groups to be less likely to receive hospice care than the majority populations in their

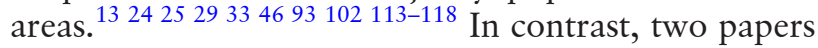
reported some minority groups to be more likely to receive hospice care than their local majority populations. ${ }^{119} 120$

In the UK, reduced access has been reported for a Pakistani/Indian/Bangladeshi groups ${ }^{113}$ and Caribbean/Chinese/African groups. ${ }^{116}$ Other studies have reported this not to be the case. ${ }^{34120121}$

In Australia, indigenous populations are less likely to receive hospice care,, 254647102122 or if a patient's informal carer has a non-English speaking background. ${ }^{13} 123$ The New Zealand Maori population is similarly less likely to receive hospice care. ${ }^{33}$

No research was identified concerning access to hospice care for travellers and prisoners: one study of homeless people reported limited access. ${ }^{124}$

\section{Geography}

Many papers evidenced geographical factors to influence receipt of hospice care. ${ }^{15} 16111123$ Access is greater for those living in urban areas, with closer proximity to a hospice and associated services in Australia, ${ }^{23} 28294445102123125126$ Canada $^{158293}$ and the UK. ${ }^{11} 3441110127-129$ Availability of services also varies considerably between regions and countries, ${ }^{11} 3441103110127-130$ which may act as a barrier to General Practitioner (GP) referral. ${ }^{131}$ 


\section{Socioeconomic status}

Many, mostly high WoE studies reveal lower hospice access for people living in areas of lower socioeconomic status (SES). ${ }^{11} 1316313245-4793100102120123127128$ 132-137 In the UK between 1993 and 2012, the proportion of hospice inpatients from the most deprived quintile reduced, while the proportion from the most affluent quintile increased. ${ }^{31}$ However, several high WoE studies have found no association between SES and access. ${ }^{28} 293891949699107108111138$ In fact, some studies report greater access among those from lower SES areas. ${ }^{41} 103$

\section{Other factors}

Further factors identified while reviewing the above literature, but neither searched for systematically nor included in the synthesis included: negative public and professional attitudes towards hospice; ${ }^{139-142}$ limited awareness of hospice services; ${ }^{139-141}{ }^{143-146}$ the challenges of difficult conversations surrounding the term 'hospice, 139140 and the extent or lack of a patient' social support networks. ${ }^{13143147148}$ There is a web of multicollinearity between these factors and the demographic variables highlighted above.

\section{DISCUSSION}

\section{Summary of findings}

This review identifies that the literature evidences that certain groups continue to have unequal access to hospice care; the oldest old, ethnic minorities, people with non-cancer illness, those living in rural areas and areas of social deprivation. The literature concerning gender and marital status is inconsistent. The potential factors influencing the findings of this review, and how they might be addressed are explored below.

\section{Strengths and limitations}

This major systematic review has brought together the heterogeneous literature concerning access to hospice care up to late 2019. At times it was unclear how authors from different countries were using the term 'hospice'; broad inclusion criteria for 'hospice care' were employed, including inpatient beds, outpatient, day care, community specialist palliative care and hospice-at-home services while seeking to exclude palliative care wards in hospitals, care homes or other long-term care institutions.

\section{Diagnosis, institutional culture and prognosis}

Continuing greater access to hospice care of patients with cancer reflects a persistence of the early focus of the hospice movement on cancer care and the final period of life. The more predictable cancer dying trajectory ${ }^{149} 150$ facilitates easier recognition of the final phase of life, better suiting time-limited hospice care. The greater prognostic uncertainty for people with chronic chest and heart disease, dementia or frailty of old age inhibits timely end of life care discussions and planning and is a continuing barrier to accessing hospice care. Despite their high symptom burden, ${ }^{9}$ the prolonged needs of patients without cancer and difficulties in determining when the terminal stage has been entered, leads to late or no hospice referral. ${ }^{146151}$

The fact that hospice care in practice continues to primarily address the needs of patients with cancer has been described as an 'historical anachronism'. ${ }^{152}$ A new model of hospice care is urgently needed in which the historical cancer-appropriate 'one-size-fits-all' framework $^{153}$ is reorganised to prioritise whichever patients need it the most ${ }^{152}$ and to better identify those patients with non-cancer illnesses who would benefit from hospice care. ${ }^{154}$ The needs of the growing number of people approaching the end of their lives with multimorbidity and frailty presents a major challenge to health and social care services in general and the hospice movement in particular. Innovative collaborative services, based around patient, family and wider community are needed to ensure optimal care for all.

Unique Nneeds

The end-of-life care needs of some groups may be better met by services other than hospice care. The oldest-old, who are under-represented in hospices, may find their long-term care needs, associated with frailty and dementia are better addressed in a care home setting rather than hospice. ${ }^{155}$ Many patients approaching the end of life may neither require nor desire specialist palliative care provision from hospice teams, preferring to continue to receive care from their General Practitioner and Community Nursing Team, with whom they have longstanding trusting relationships. Innovative and collaborative models of working are required; in many cases, hospice teams will have more of an educational role rather than direct care provision.

For some groups, therefore, lower use of hospice services may reflect care preferences and choices rather than inequality of provision. Ethnic minority groups also have particular needs at the end of life, including cultural and family expectations and religious practices around dying. ${ }^{121}$ Indigenous Australians focus on maintaining spiritual connection to the land and on receiving culturally tailored care from members of the community. ${ }^{156}{ }^{157}$ However, for LGBTQ+ groups, concerns over social prejudice may affect access to hospice care in addition to particular care needs. ${ }^{158-160}$

Greater focus is needed on addressing the needs of minority groups; sensitive involvement of these communities in service codesign is required. 'Homelike' hospice services are needed for rural and less affluent patients as well as increased sensitivity towards the needs of LGBTQ+ patientsand ethnic minority groups. The growing numbers of people reaching the end of their lives in multimorbid frail old-age is a challenge that hospice services need to address urgently. ${ }^{161}$ 
Public awareness of hospice care

A third factor involves different levels of public awareness of what hospice care provides and for whom. Variation in health literacy and knowledge of health services is present across ethnic minorities and socioeconomic groups. ${ }^{114}$ 162-165 The greater access to hospice care by people in more affluent groups may in part reflect their greater health literacy and the presence of articulate relatives who can advocate for hospice services they know to be available.

Similarly, the concentration of hospices in metropolitan areas limits rural patients' exposure to and knowledge of hospice care. Travelling times further exacerbate impaired access, alongside lack of transport links for relatives. ${ }^{129} 165$

Hospices need to improve their links with the diverse social and cultural groups in the areas they serve, focusing on enhancing their awareness of available hospice services. Particular focus is needed on reaching out beyond affluent metropolitan areas into deprived and rural populations, supported by telehealth and video consultations. ${ }^{47} 122$

The inequalities highlighted in this review are not just the responsibility of the hospice movement. System leaders, health and social care managers, policy makers and commissioners need to recognise and understand that while hospices have a vital contribution to palliative and end of life care provision, meeting patient and family needs requires a collaborative and innovative whole-systems approach.

\section{Future research}

This review has highlighted a number of areas in which the current literature is absent or very limited, including optimal ways to support ethnic minority groups, homeless people, LGBTQ+ populations, HIV, diabetes and cystic fibrosis.

\section{CONCLUSION}

This systematic literature review highlights the persisting unequal access to hospice services for many groups: people with non-malignant disease, the oldest-old, ethnic minorities, living in rural and socioeconomically deprived areas, are consistently reported to be referred to or to die in hospice less frequently. A combination of prognostic uncertainty, institutional cultures, unique needs of particular groups and a lack of public awareness of services exacerbate these problems. Equity of access for all is urgently needed, with innovative and collaborative services developed to meet the diverse needs of the whole community.

Equity of access for all remains a challenge for the hospice movement.

\section{Twitter Isla Kuhn@ilk21}

Acknowledgements We are grateful for the administrative support of Angela Harper throughout this review project.
Contributors JT, ST, IK and SB contributed to study design. IK conducted the database searches. JT, ST, AR, AK and IW contributed to screening of titles and abstracts and data extraction. All the authors contributed to the synthesis and have approved the paper.

Funding SB and IW are funded by the National Institute for Health Research (NIHR) Applied Research Collaboration East of England (ARC EoE) programme (NIHR200177).

Disclaimer The views expressed are those of the author(s) and not necessarily those of the NHS, the NIHR or the Department of Health and Social Care.

Competing interests None declared.

Patient consent for publication Not required.

Provenance and peer review Not commissioned; externally peer reviewed.

Open access This is an open access article distributed in accordance with the Creative Commons Attribution Non Commercial (CC BY-NC 4.0) license, which permits others to distribute, remix, adapt, build upon this work noncommercially, and license their derivative works on different terms, provided the original work is properly cited, appropriate credit is given, any changes made indicated, and the use is noncommercial. See: http://creativecommons.org/licenses/by-nc/4. $0 /$.

ORCID iD

Stephen Barclay http://orcid.org/0000-0002-4505-7743

\section{REFERENCES}

1 Office for National Statistics. Deaths registered in Engand and Wales 20192020.

2 Office for National Statistics. Deaths registered in England and Wales 2020.

3 Department of Health. End of life care strategy: promoting high quality care for all adults at the end of life 2008.

4 National Palliative and End of Life Care Partnership. Ambitions for palliative and end of life care: a national framework for local action 2015-2020 2015.

5 Dixon J KD, Mastosevic T, Clark M, et al. Equity in the provision of palliative care in the UK: review of evidence 2015.

6 Petticrew P RH. Systematic Reviews in the Social Sciences. Blackwell Publishing: Oxford, 2005.

7 Popay J RH, Sowden A, et al. Guidance on the conduct of narrative synthesis in systematic reviews. Lancaster University, 2006.

8 Gough D. Weight of evidence: a framework for the appraisal of the quality and relevance of evidence. Res Pap Educ 2007;22:213-28.

9 Addington-Hall J, Fakhoury W, McCarthy M. Specialist palliative care in nonmalignant disease. Palliat Med 1998;12:417-27.

10 Bennett MI, Ziegler L, Allsop M, et al. What determines duration of palliative care before death for patients with advanced disease? A retrospective cohort study of community and hospital palliative care provision in a large UK City. BMJ Open 2016;6:e012576.

11 Buck J, Webb L, Moth L, et al. Persistent inequalities in hospice at home provision. BMJ Support Palliat Care 2020;10:e23.

12 Cox S, Murtagh FEM, Tookman A, et al. A review of specialist palliative care provision and access across London mapping the capital. London J Prim Care 2017;9:33-7.

13 Currow DC, Agar M, Sanderson C, et al. Populations who die without specialist palliative care: does lower uptake equate with unmet need? Palliat Med 2008;22:43-50. 
14 Currow DC, Burns CM, Abernethy AP. Place of death for people with noncancer and cancer illness in South Australia: a population-based survey. J Palliat Care 2008;24:144-50.

15 Gao J, Johnston GM, Lavergne MR, et al. Identifying population groups with low palliative care program enrolment using classification and regression tree analysis. $J$ Palliat Care 2011;27:98-106.

16 Gao Wet al. Changing patterns in place of cancer death in England: a population-based study. Plos Medicine 2013;10.

17 Gao Wet al. Health Services and Delivery Research, in Geographical and temporal Understanding In place of Death in England (1984-2010): analysis of trends and associated factors to improve end-of-life Care (GUIDE_Care) - primary research. Southampton (UK: NIHR Journals Library, 2014.

18 Gilbert RJ, Nekolaichuk C, Fainsinger RL. Increased noncancer admissions to hospice palliative care units-will this hurt cancer care? Palliat Med 2010;1:S176.

19 Gomes B, Calanzani N, Higginson IJ. Reversal of the British trends in place of death: time series analysis 2004-2010. Palliat Med 2012;26:102-7.

20 Gomes B, Higginson IJ. Where people die (1974--2030): past trends, future projections and implications for care. Palliat Med 2008;22:33-41.

21 Grande GE, Farquhar MC, Barclay SIG, et al. The influence of patient and carer age in access to palliative care services. Age Ageing 2006;35:267-73.

22 Harrison N, Cavers D, Campbell C, et al. Are UK primary care teams formally identifying patients for palliative care before they die? Br J Gen Pract 2012;62:e344-52.

23 Hunt R, McCaul K. A population-based study of the coverage of cancer patients by hospice services. Palliat Med 1996;10:5-12.

24 McCarthy M. Hospice patients: a pilot study in 12 services. Palliat Med 1990;4:93-104.

25 McNamara B, Rosenwax L. Factors affecting place of death in Western Australia. Health Place 2007;13:356-67.

26 Napolskikh J, Selby D, Bennett M, et al. Demographic profile and utilization statistics of a Canadian inpatient palliative care unit within a tertiary care setting. Curr Oncol 2009;16:49-54.

27 Pivodic L, Pardon K, Morin L, et al. Place of death in the population dying from diseases indicative of palliative care need: a cross-national population-level study in 14 countries. J Epidemiol Community Health 2016;70:17-24.

28 Rosenwax L, Spilsbury K, McNamara BA, et al. A retrospective population based cohort study of access to specialist palliative care in the last year of life: who is still missing out a decade on? BMC Palliat Care 2016;15:46.

29 Rosenwax LK, McNamara BA. Who receives specialist palliative care in Western Australia--and who misses out. Palliat Med 2006;20:439-45.

30 Sharpe A, Hiersche A, Mason L. "Don't leave me this way": Recognising the unrecognised need for specialist palliative care in the general hospital population. Palliative Medicine 2016;30:S95.

31 Sleeman KE, Davies JM, Verne J, et al. The changing demographics of inpatient hospice death: population-based cross-sectional study in England, 1993-2012. Palliat Med 2016;30:45-53.

32 Sleeman KEet al. Reversal of English trend towards Hospital death in dementia: a population-based study of place of death and associated individual and regional factors, 2001-2010. BMC Neurology 2014;14.

33 Taylor EJ, Ensor B, Stanley J. Place of death related to demographic factors for hospice patients in Wellington, Aotearoa New Zealand. Palliat Med 2012;26:342-9.

34 Allsop MJ, Ziegler LE, Mulvey MR, et al. Duration and determinants of hospice-based specialist palliative care: a national retrospective cohort study. Palliat Med 2018;32:1322-33.

35 Currow DC, Abernethy AP, Fazekas BS. Specialist palliative care needs of whole populations: a feasibility study using a novel approach. Palliat Med 2004;18:239-47.

36 Kelly J OCD. The dementia patient's pathway through the Specialist Palliative Care services Part i. Eur J Palliat Care 2018;25.

37 Verne J. Increasing numbers of colorectal cancer patients are dying at home or in care homes in England over the past decade: P262. Colorectal Disease 2013;15.

38 Addington-Hall J, Altmann D. Which terminally ill cancer patients in the United Kingdom receive care from community specialist palliative care nurses? J Adv Nurs 2000;32:799-806.

39 Ansell P, Howell D, Garry A, et al. What determines referral of UK patients with haematological malignancies to palliative care services? an exploratory study using Hospital records. Palliat Med 2007;21:487-92.

40 Auret K, Bulsara C, Joske D. Australasian haematologist referral patterns to palliative care: lack of consensus on when and why. Intern Med J 2003;33:566-71.

41 Gatrell AC, Harman JC, Francis BJ, et al. Place of death: analysis of cancer deaths in part of North West England. J Public Health Med 2003;25:53-8.

42 Howell DA. Place of death in haematological malignancy: variations by disease sub-type and time from diagnosis to death. BMC Palliat Care 2013;12:42.

43 Howell DA, Wang H-I, Roman E, et al. Variations in specialist palliative care referrals: findings from a population-based patient cohort of acute myeloid leukaemia, diffuse large B-cell lymphoma and myeloma. BMJ Support Palliat Care 2015;5:496-502.

44 Hunt R, Bonett A, Roder D. Trends in the terminal care of cancer patients: South Australia, 1981-1990. Aust N Z J Med 1993;23:245-51.

45 Hunt R, McCaul K. Coverage of cancer patients by hospice services, South Australia, 1990 to 1993. Aust N Z J Public Health 1998;22:45-8.

46 Hunt RW, Fazekas BS, Luke CG, et al. Where patients with cancer die in South Australia, 1990-1999: a population-based review. Med J Aust 2001;175:526-9.

47 Hunt RW, D'Onise K, Nguyen A-MT, et al. Where patients with cancer die: a population-based study, 1990 to 2012. J Palliat Care 2019;34:224-31.

48 Johnston GM, Gibbons L, Burge FI, et al. Identifying potential need for cancer palliation in nova Scotia. CMAJ 1998;158:1691-8.

49 Vidrine J, Hurst E, Pelham A. Place of death in patients with haematological malignancy in the north-east of England: where does this happen and what factors may influence this? Br J Haematol 2016;173:33.

50 Campbell RTet al. Discrepancy between preferred and actual place of death in patients with acute heart failure. Eur J Heart Fail 2014;16:122.

51 Cheang MH, Rose G, Cheung C-C, et al. Current challenges in palliative care provision for heart failure in the UK: a survey on the perspectives of palliative care professionals. Open Heart 2015;2:e000188.

52 French M, Owles H, Baxter AJ. Where do elderly patients with heart failure die? Age and Ageing 2011;40:23.

53 Gibbs LME, Khatri AK, Gibbs JSR. Survey of specialist palliative care and heart failure: September 2004. Palliat Med 2006;20:603-9.

54 Horne G, Payne S. Removing the boundaries: palliative care for patients with heart failure. Palliat Med 2004;18:291-6.

55 Chen JJet al. General practitioner perceptions of services for patients with advanced heart failure: a qualitative study. Eur J Heart Fail 2017;19:406-7. 
56 Jones S. Palliative care in terminal cardiac failure. BMJ 1995;310:805.

57 Kaul Pet al. Home, hospital or hospice? trends and predictors of location of death among patients with heart failure and acute coronary syndromes. European Heart Journal 2016;37:532.

58 McKinley RK, Stokes T, Exley C, et al. Care of people dying with malignant and cardiorespiratory disease in general practice. Br J Gen Pract 2004;54:909-13.

59 Murray SA. Dying of lung cancer or cardiac failure: prospective qualitative interview study of patients and their carers in the community. BMJ 2002;25:929.

60 Thorns AR, Gibbs LM, Gibbs JS. Management of severe heart failure by specialist palliative care. Heart 2001;85:93.

61 Woolcock S, De Soyza J, Crackett R, et al. P160 the role of specialist palliative care services in the management of patients with pulmonary arterial hypertension; a review of current practice. Thorax 2014;69:A144.

62 Addy C, Bell NJ, Bateman K. WS5.3 improving care for adults with end stage cystic fibrosis at Bristol adult CF centre (BACFC). J Cyst Fibros 2014;13:S10.

63 Cohen J, Beernaert K, Van den Block L, et al. Differences in place of death between lung cancer and COPD patients: a 14-country study using death certificate data. NPJ Prim Care Respir Med 2017;27:14.

64 Edmonds P, Karlsen S, Khan S, et al. A comparison of the palliative care needs of patients dying from chronic respiratory diseases and lung cancer. Palliat Med 2001;15:287-95.

65 Elkington $\mathrm{H}$, White P, Addington-Hall J, et al. The healthcare needs of chronic obstructive pulmonary disease patients in the last year of life. Palliat Med 2005;19:485-91.

66 Gore JM, Brophy CJ, Greenstone MA. How well do we care for patients with end stage chronic obstructive pulmonary disease (COPD)? A comparison of palliative care and quality of life in COPD and lung cancer. Thorax 2000;55:1000-6.

67 Hayle Cet al. Palliative care for patients with COPD: the impact of collaborative working in Salford. Palliat Med 2010;24:242.

68 Higginson IJet al. Which patients with advanced respiratory disease die in hospital? A 14-year population-based study of trends and associated factors. BMC Medicine 2017;15.

69 Veigh CM, Reid J, Larkin P, et al. The provision of generalist and specialist palliative care for patients with non-malignant respiratory disease in the North and Republic of ireland: a qualitative study. BMC Palliat Care 2017;17:6.

70 Partridge MR, Khatri A, Sutton L, et al. Palliative care services for those with chronic lung disease. Chron Respir Dis 2009;6:13-17.

71 Smallwood Net al. Palliation of patients with chronic obstructive pulmonary disease at the end of life. Respirology 2016;21:143.

72 Gunda S, Thomas M, Smith S. National survey of palliative care in end-stage renal disease in the UK. Nephrol Dial Transplant 2005;20:392-5.

73 Hobson K, Gomm S, Murtagh F, et al. National survey of the current provision of specialist palliative care services for patients with end-stage renal disease. Nephrol Dial Transplant 2011;26:1275-81.

74 Hussain JA, Mooney A, Russon L. Comparison of survival analysis and palliative care involvement in patients aged over 70 years choosing conservative management or renal replacement therapy in advanced chronic kidney disease. Palliat Med 2013;27:829-39.

75 Lovell N, Jones C, Baynes D, et al. Understanding patterns and factors associated with place of death in patients with end-stage kidney disease: a retrospective cohort study. Palliat Med 2017;31:283-8.
76 Okamoto I, Tonkin-Crine S, Rayner H, et al. Conservative care for ESRD in the United Kingdom: a national survey. Clin J Am Soc Nephrol 2015;10:120-6.

77 Morton RL, Webster AC, McGeechan K, et al. Conservative management and end-of-life care in an Australian cohort with ESRD. Clin J Am Soc Nephrol 2016;11:2195-203.

78 Bablitz C, Tarumi Y, Watanabe S, et al. P169 high cage score and late referral pattern typify end-stage liver failure patients referred to a regional palliative care program. J Pain Symptom Manage 2016;52:e111.

79 Low J, Vickerstaff V, Davis S, et al. Palliative care for cirrhosis: a UK survey of health professionals' perceptions, current practice and future needs. Frontline Gastroenterol 2016;7:4-9.

80 Low J, Davis S, Vickerstaff V, et al. Advanced chronic liver disease in the last year of life: a mixed methods study to understand how care in a specialist liver unit could be improved. BMJ Open 2017;7:e016887.

81 Poonja Z, Brisebois A, van Zanten SV, et al. Patients with cirrhosis and denied liver transplants rarely receive adequate palliative care or appropriate management. Clin Gastroenterol Hepatol 2014;12:692-8.

82 Crowther J, Wilson KCM, Horton S, et al. Palliative care for dementia--time to think again? OJM 2013;106:491-4.

83 Houttekier D, Cohen J, Bilsen J, et al. Place of death of older persons with dementia. A study in five European countries. $J$ Am Geriatr Soc 2010;58:751-6.

84 Zheng Let al. How good is primary care at identifying patients who need palliative care? a mixed methods study. Eur J Palliat Care 2013;20:216-22.

85 Chaudri MB, Kinnear WJM, Jefferson D. Patterns of mortality in patients with motor neurone disease. Acta Neurol Scand 2003;107:50-3.

86 O'Brien T, Kelly M, Saunders C. Motor neurone disease: a hospice perspective. BMJ 1992;304:471-3.

87 Sleeman KE, Ho YK, Verne J, et al. Place of death, and its relation with underlying cause of death, in Parkinson's disease, motor neurone disease, and multiple sclerosis: a population-based study. Palliat Med 2013;27:840-6.

88 Martin JE, Raffel J, Nicholas R. Progressive Dwindling in multiple sclerosis: an opportunity to improve care. PLoS One 2016;11:e0159210.

89 Chochinov HMet al. Comparative health care use patterns of people with schizophrenia near the end of life: a populationbased study in Manitoba, Canada. Schizophr Res 2012;141:p. 241-6.

90 Butler H, O'Brien AJ. Access to specialist palliative care services by people with severe and persistent mental illness: a retrospective cohort study. Int J Ment Health Nurs 2018;27:737-46.

91 Addington-Hall J, Altmann D, McCarthy M. Which terminally ill cancer patients receive hospice in-patient care? Soc Sci Med 1998;46:1011-6.

92 Burge F, Johnston G, Lawson B, et al. Population-Based trends in referral of the elderly to a comprehensive palliative care programme. Palliat Med 2002;16:255-6.

93 Burge FI, Lawson BJ, Johnston GM, et al. A population-based study of age inequalities in access to palliative care among cancer patients. Med Care 2008;46:1203-11.

94 Burt K, Conway R, Douglas C. Deprivation scores and access to specialist palliative care services in cancer patients in Dundee. Palliat Med 2010;24:S172.

95 Cartwright A. Dying when you're old. Age Ageing 1993;22:425-30.

96 Davies E, Linklater KM, Jack RH, et al. How is place of death from cancer changing and what affects it? analysis of cancer registration and service data. Br J Cancer 2006;95:593-600. 
97 Evans CJ, Ho Y, Daveson BA, et al. Place and cause of death in centenarians: a population-based observational study in England, 2001 to 2010. PLoS Med 2014;11:e1001653.

98 Fleming J ZJ, Farquhar M, Brayne C. Barclay S and the Cambridge City over 75 s Cohort (CC\&\%C) study collaboration, Place of death for the 'oldest old': $\geq 85$-yearolds in the CC75C population-based cohort. Br J Gen Pract 2010;60:e171-9.

99 Gray JD, Forster DP. Factors associated with utilization of specialist palliative care services: a population based study. $J$ Public Health Med 1997;19:464-9.

100 Kessler D, Peters TJ, Lee L, et al. Social class and access to specialist palliative care services. Palliat Med 2005;19:105-10.

101 Lock A, Higginson I. Patterns and predictors of place of cancer death for the oldest old. BMC Palliat Care 2005;4:6.

102 McNamara B, Rosenwax L. Specialist palliative care use for people dying of cancer in Western Australia. Cancer Forum 2007;31:18-22.

103 O'Dowd EL, McKeever TM, Baldwin DR, et al. Place of death in patients with lung cancer: a retrospective cohort study from 2004-2013. PLoS One 2016;11:e0161399.

104 Ziegler L CC, West R, Hurlow A. Age Variation in the Care from Diagnosis to Death for Cancer Patients: A Retrospective Longitudinal Study in a UK Cancer Population, in 10th World Research Congress of the European Association for Palliative Care (EAPC. Bern: Palliative Medicine, 2018: 3-330.

105 Verne J PA, Pignatelli I. What Does National Mortality Data Tell Us about Where Head and Neck Cancer Patients Die and What Influences This?, in 10th World Research Congress of the European Association for Palliative Care (EAPC. Bern: Palliative Medicine, 2018: 3-330.

106 Kamisetty A, Magennis P, Mayland C, et al. Where do patients treated for oral cancer die? A 20-year cohort study 1992-2011. Br J Oral Maxillofac Surg 2015;53:1015-20.

107 Burt J, Plant H, Omar R, et al. Equity of use of specialist palliative care by age: cross-sectional study of lung cancer patients. Palliat Med 2010;24:641-50.

108 Kamisetty A, Magennis P, Lowe D, et al. Place of death of oral and oropharyngeal squamous cell carcinoma (OOSCC) patients 1992-2009: who dies at home? J Oral Maxillofac Surg 2011;49:S9.

109 Bradshaw PJ. Characteristics of clients referred to home, hospice and hospital palliative care services in Western Australia. Palliat Med 1993;7:101-7.

110 Madden P, Coupland V, Møller H, et al. Using maps and funnel plots to explore variation in place of death from cancer within London, 2002-2007. Palliat Med 2011;25:323-32.

111 Davison D, Johnston G, Reilly P, et al. Where do patients with cancer die in Belfast? Ir J Med Sci 2001;170:18-23.

112 Dunphy KP, Amesbury BDW. A comparison of hospice and home care patients: patterns of referral, patient characteristics and predictors of place of death. Palliat Med 1990;4:105-11.

113 Coupland VH, Madden P, Jack RH, et al. Does place of death from cancer vary between ethnic groups in South East England? Palliat Med 2011;25:314-22.

114 Gaffin J, Hill D, Penso D. Opening doors: improving access to hospice and specialist palliative care services by members of the black and minority ethnic communities. commentary on palliative care. Br J Cancer Suppl 1996;29:S51-3.

115 Karim K, Bailey M, Tunna K. Nonwhite ethnicity and the provision of specialist palliative care services: factors affecting doctors' referral patterns. Palliat Med 2000;14:471-8.

116 Koffman J, Higginson IJ. Dying to be home? preferred location of death of first-generation black Caribbean and native-born white patients in the United Kingdom. J Palliat Med 2004;7:628-36.
117 Koffman J, Ho YK, Davies J, et al. Does ethnicity affect where people with cancer die? a population-based 10 year study. PLoS One 2014;9:e95052.

118 Worth A, Irshad T, Bhopal R, et al. Vulnerability and access to care for South Asian Sikh and Muslim patients with life limiting illness in Scotland: prospective longitudinal qualitative study. BMJ 2009;338:b183.

119 Fountain A. Ethnic minorities and palliative care in Derby. Palliat Med 1999;13:161-2.

120 Sharpe KH, Cezard G, Bansal N, et al. Policy for home or hospice as the preferred place of death from cancer: Scottish health and ethnicity linkage study population cohort shows challenges across all ethnic groups in Scotland. BMJ Support Palliat Care 2015;5:443-51.

121 Verne J PA, Bowtell N. Choice and place of death: does ethnicity affect where people die? insights from routine data analysis, in 10th world research Congress of the European association for palliative care (EAPC. Bern: Palliative Medicine, 2018: 3-330.

122 Waran E, Zubair MY, O'Connor N. The gap reversed: a review of site of death in the top end. Med J Aust 2017;207:39

123 Currow DC, Allingham S, Bird S, et al. Referral patterns and proximity to palliative care inpatient services by level of socio-economic disadvantage. A national study using spatial analysis. BMC Health Serv Res 2012;12:424.

124 Shulman C, Hudson BF, Low J, et al. End-Of-Life care for homeless people: a qualitative analysis exploring the challenges to access and provision of palliative care. Palliat Med 2018;32:36-45.

125 Burns CM, Dal Grande E, Tieman J, et al. Who provides care for people dying of cancer? A comparison of a rural and metropolitan cohort in a South Australian bereaved population study. Aust J Rural Health 2015;23:24-31.

126 Rainsford S, Glasgow NJ, MacLeod RD, et al. Place of death in the Snowy Monaro region of new South Wales: a study of residents who died of a condition amenable to palliative care. Aust J Rural Health 2018;26:126-33.

127 Gatrell AC, Wood DJ. Variation in geographic access to specialist inpatient hospices in England and Wales. Health Place 2012;18:832-40.

128 Wood DJ, Clark D, Gatrell AC. Equity of access to adult hospice inpatient care within north-west England. Palliat Med 2004;18:543-9.

129 Chukwusa E, Verne J, Polato G, et al. Urban and rural differences in geographical accessibility to inpatient palliative and end-of-life (PEoLC) facilities and place of death: a national population-based study in England, UK. Int J Health Geogr 2019;18:8.

130 O'Dowd ELet al. Place and cause of death in patients with lung cancer in the United Kingdom. J Thorac Oncol 2015;2:S518.

131 Seamark DA, Thorne CP, Lawrence C, et al. Appropriate place of death for cancer patients: views of general practitioners and hospital doctors. Br J Gen Pract 1995;45:359-63.

132 Campbell M, Grande G, Wilson C, et al. Exploring differences in referrals to a hospice at home service in two socio-economically distinct areas of Manchester, UK. Palliat Med 2010;24:403-9.

133 Cartwright A. Social class differences in health and care in the year before death. J Epidemiol Community Health 1992;46:54-7.

134 Cunningham CM, Hanley GE, Morgan SG. Income inequities in end-of-life health care spending in British Columbia, Canada: a cross-sectional analysis, 2004-2006. Int J Equity Health 2011;10:12.

135 Sims A, Radford J, Doran K, et al. Social class variation in place of cancer death. Palliat Med 1997;11:369-73. 
136 Macfarlane M, Carduff E. Does place of death vary by deprivation for patients known to specialist palliative care services? BMJ Support Palliat Care 2018;8:428-30.

137 Bowers Set al. Socioeconomic status is associated with place of death in patients known to hospice services. Scott Med J 2018;63:53

138 Ziwary SR, Samad D, Johnson CD, et al. Impact of place of residence on place of death in Wales: an observational study. BMC Palliat Care 2017;16:72.

139 McCaughan D, Roman E, Smith AG, et al. Palliative care specialists' perceptions concerning referral of haematology patients to their services: findings from a qualitative study. BMC Palliat Care 2018;17:33.

140 McCaughan D, Roman E, Smith AG, et al. Haematology nurses' perspectives of their patients' places of care and death: a UK qualitative interview study. Eur J Oncol Nurs 2019;39:70-80.

141 Gerber K, Hayes B, Bryant C. 'It all depends!': a qualitative study of preferences for place of care and place of death in terminally ill patients and their family caregivers. Palliat Med 2019;33:802-11.

142 Kelly J OCD. The dementia patient's pathway through Specialist Palliative Care services - Part II. Eur J Palliat Care 2018;25:93-5.

143 McCaughan D, Roman E, Smith AG, et al. Perspectives of bereaved relatives of patients with haematological malignancies concerning preferred place of care and death: a qualitative study. Palliat Med 2019;33:518-30.

144 Pugh A, Castleden H, Giesbrecht M, et al. Awareness as a dimension of health care access: exploring the case of rural palliative care provision in Canada. J Health Serv Res Policy 2019;24:108-15.

145 Crooks VA, Schuurman N, Cinnamon J, et al. Refining a location analysis model using a mixed methods approach: Community readiness as a key factor in siting rural palliative care services. J Mix Methods Res 2011;5:77-95.

146 Ferrera-Reid R. Access barriers to hospice care for noncancer conditions. J Hosp Palliat Nurs 2004;6:103-7.

147 Burns CM, Abernethy AP, Leblanc TW, et al. What is the role of friends when contributing care at the end of life? findings from an Australian population study. Psychooncology $2011 ; 20: 203-12$

148 Johnson MJ, Allgar V, Chen $\mathrm{H}$, et al. The complex relationship between household income of family caregivers, access to palliative care services and place of death: a national household population survey. Palliat Med 2018;32:357-65.

149 Murray SA, Kendall M, Boyd K, et al. Illness trajectories and palliative care. BMJ 2005;330:1007-11.

150 Lunney JR, Lynn J, Foley DJ, et al. Patterns of functional decline at the end of life. JAMA 2003;289:2387-92.
151 Almack K. Uncertain trajectories in old age and implications for families and for palliative and end of life care policy and practice. Death Stud 2019:1-10.

152 Abel J, Kellehear A. Palliative care reimagined: a needed shift. BMJ Support Palliat Care 2016;6:21-6.

153 Warraich HJ, Allen LA, Mukamal KJ, et al. Accuracy of physician prognosis in heart failure and lung cancer: comparison between physician estimates and model predicted survival. Palliat Med 2016;30:684-9.

154 Murray S. Dead unequal. Br J Gen Pract 2017;67:112.2-112.

155 Lee RP, Bamford C, Poole M, et al. End of life care for people with dementia: the views of health professionals, social care service managers and frontline staff on key requirements for good practice. PLoS One 2017;12:e0179355.

156 Waran E, O'Connor N, Zubair MY, et al. 'Finishing up' on country: challenges and compromises. Intern Med J 2016;46:1108-11.

157 McGrath PD, Patton MAS, Ogilvie KF, et al. The case for Aboriginal health workers in palliative care. Aust Health Rev 2007;31:430-9.

158 Bristowe K, Hodson M, Wee B, et al. Recommendations to reduce inequalities for LGBT people facing advanced illness: ACCESSCare national qualitative interview study. Palliat Med 2018;32:23-35.

159 Clift JB, Kirby J. Health care access and perceptions of provider care among individuals in same-sex couples: findings from the medical expenditure panel survey (MEPS). $J$ Homosex 2012;59): :839-50.

160 Hutchinson MK, Thompson AC, Cederbaum JA. Multisystem factors contributing to disparities in preventive health care among lesbian women. J Obstet Gynecol Neonatal Nurs 2006;35:393-402.

161 Pollock K, Seymour J. Reappraising 'the good death' for populations in the age of ageing. Age Ageing 2018;47:328-30.

162 Seymour J, Payne S, Chapman A, et al. Hospice or home? expectations of end-of-life care among white and Chinese older people in the UK. Sociol Health Illn 2007;29:872-90.

163 Koffman J, Camps M. No way in: including the excluded at the end of life. Palliative care nursing principles and evidence for practice. Buckingham: Open University Press, 2004: 364-84.

164 Baker DW, Wolf MS, Feinglass J, et al. Health literacy and mortality among elderly persons. Arch Intern Med 2007;167:1503-9.

165 Lewis JM, DiGiacomo M, Currow DC, et al. Dying in the margins: understanding palliative care and socioeconomic deprivation in the developed world. J Pain Symptom Manage 2011;42:105-18. 